\title{
ATENUACIÓN, GÉNERO INTENSIFICACIÓN EN EL DISCURSO POLÍTICO: LAS REACCIONES MEDIÁTICAS DEL CASO DE UNA LEGISLADORA DE NUEVO LEÓN, MÉXICO (2015)
}

ATTENUATION, GENDER AND INTENSIFICATION IN POLITICAL DISCOURSE: THE MEDIA REACTION IN THE CASE OF A CONGRESSWOMAN OF NUEVO LEON, MEXICO (2015)

\section{Olga Nelly EstRADA / Griselda ZÁRATE}

Universidad Autónoma de Nuevo León / Universidad de Monterrey

\section{Resumen:}

El presente estudio constituye un primer acercamiento al análisis del fenómeno pragmático de la atenuación e intensificación en la argumentación (Zárate, 2015; Toulmin, Rieke y Janik, 1979; Gilbert, 1997) y también a las posibles relaciones entre evidencialidad y epistemicidad (De Haan, 1999), presentes en el discurso político y de género (Estrada, 2012) en el entendido que todo acto de habla implica una amenaza, por ende, un acto de poder (Briz, 2001), aplicado al caso de una legisladora que rompe con el protocolo dentro de la Cámara de Diputados en el último informe del gobernador al mostrar una pancarta que dice «No pasaran [sic] las cuentas mochas» (Benvenutti, 2015). Se presentan las reacciones mediáticas en dos artículos, en la revista Proceso y el periódico El Norte, así como la réplica que hizo la diputada en las redes sociales para defender su cargo como legisladora el 28 de septiembre 2015.

PaLABRAS CLAVE: atenuación, género, legisladora, medios.
Abstract:

This paper is a first approach to the analysis of pragmatic attenuation and intensification in argumentation (Zárate 2015; Toulmin, Rieke and Janik 1979; Gilbert 1997), through cognitive metaphors (Lakoff y Johnson 1980) and also possible links between evidentiality and epistemicity (De Haan 1999), in political and gender discourse (Estrada, 2012) in the understanding that all speech act implies a threat, and thus, a power act (Briz, 2001). This is applied to the case of a Congresswoman who breaks the protocol during the Governor's last speech before the state Congress: «No pasarán las cuentas mochas» [«Blunt accounts will not pass") (Benvenutti, 2015). Two articles of media discourse are analyzed, one from Proceso and one from Quorum Informativo, as well as Congresswoman Benvenutti's rebuttal in her Facebook private account on September 28, 2015.

KEY WORDS: attenuation, gender, congresswoman, media 


\section{$1 \quad$ INTRODUCCIÓN}

Este trabajo analiza el fenómeno pragmático de la atenuación e intensificación en la argumentación del discurso político y de género. Asimismo, se analizan las formas de evidencialidad y epistemicidad en los diálogos emitidos en los medios mexicanos aplicados al caso de la diputada local Marlene Benvenutti quien rompe con el protocolo establecido dentro de la Cámara de Diputados en el último informe del gobernador de Nuevo León, México, Rodrigo Medina, en 2015. Por primera vez, una legisladora se levanta de su curul y se coloca al lado de la máxima figura del poder para reclamar contra actos de corrupción en el Estado con una pancarta que decía «No pasarán las cuentas mochas». La diputada Benvenutti infringe el estereotipo de habla que tradicionalmente se asigna a su sexo de permanecer callada ante la autoridad establecida (Estrada y Ochoa, 2013). Esta frase molestó al gobierno en turno y cuatro días después fueron divulgadas anónimamente dos fotografías de la legisladora en lencería en las redes sociales y en los medios masivos de comunicación, a nivel local y nacional. La mayoría de las notas periodísticas refieren solamente el cuestionamiento sobre su modelaje en el pasado sin emitir juicios de valor; sin embargo, algunas de estas notas, a consecuencia de lo anterior sí comprometen el desempeño como joven política de la legisladora como una manera de dañar su imagen ante la opinión pública. Ante estos acontecimientos, como señala Briz, puede decirse que todo acto de habla implica una amenaza, por ende, un acto de poder (2001), en este estudio se analizan las estrategias pragmáticas de atenuación e intensificación en la argumentación que trasmitieron los medios mexicanos respecto a este evento. Se trata de dos artículos, publicados en la revista Proceso y el periódico El Norte, y también la réplica que hizo la diputada Benvenutti en las redes sociales el 28 de septiembre 2015.

\section{ANTECEDENTES}

\subsection{Contexto de la participación política de las mujeres en México}

A principios del siglo $X X$, las mujeres mexicanas demandaron participar en igualdad de circunstancias que los hombres en la construcción del país; exigieron para sí la prerrogativa a la educación, a votar y a tener la ciudadanía, como en el caso de la escritora y activista Andrea Villarreal (Zárate, 2011). En ese tiempo, como en el actual, se consideraba a las mujeres en un plano jerárquico social de menor valía que el que ocupan los hombres. En razón de la biología femenina, a las mujeres se les designó la debilidad física, la inferioridad intelectual, la belleza y la sensibilidad a las emociones. (Estrada, 2012). Se las percibía como personas incapaces de tomar decisiones sobre sí mismas o participar en la política. En tanto los hombres eran considerados como «el sabio que gobernaba el hogar» (Arrom, 1982: 498). Con estos argumentos se concluía que los hombres eran los únicos quienes deberían estar en la toma de decisiones en el país. En este sentido, Estela Serret menciona que la imagen de subordinada que la estructura sexo-género ha impuesto a las mujeres es vista regularmente como el resultado de un conjunto de prácticas discursivas que se organizan y se reproducen de manera intencionada por los sujetos beneficiados como parte de un proyecto por conservar un sistema de dominación (2006: 68).

Normas (ISSN: 2174-7245) | 
A principios de los años ochenta en el país era común la ausencia de mujeres en el Congreso del Estado y no se cuestionaba esta invisibilización femenina. En el imaginario colectivo no existía esa posibilidad, porque era adjudicada únicamente a los hombres, a pesar de la ley de igualdad y ciudadanía otorgada en 1953 a las mexicanas. No fue hasta los años noventa que se difundieron las primeras estadísticas sobre la situación de las mujeres en cuanto a representación política; solamente para dar a conocer la realidad sobre la exclusión femenina de la toma de decisiones del país y para proyectar que la igualdad ganada en la ley era un camino sinuoso muy largo aún por recorrer en la praxis cotidiana (Flores y Estrada, 2016).

Nuevo León, entidad ubicada al norte de México, ostenta el primer lugar del país en discriminar a los grupos vulnerables, así como de intolerancia hacia grupos indígenas o que tienen otra cultura, a mujeres y hombres homosexuales, de acuerdo al presidente del Consejo Nacional para Prevenir la Discriminación (CONAPRED), Ricardo Bucio Mújicas. Asimismo, enfatiza que la discriminación de género, contra las mujeres, «está omnipresente» (2012). En el Congreso de Nuevo León todavía no se aprueba la Ley contra la Discriminación, lo cual facilita que se siga discriminado y violentando a las personas vulnerables. Los resultados generales de la Encuesta Nacional sobre Discriminación en México muestran que la discriminación rebasa también el ámbito de lo individual e impide construir y mantener relaciones interpersonales basadas en el respeto, la igualdad y el reconocimiento mutuo, necesarios para el desarrollo consistente de la identificación social (ENADIS 2010).

El comité de seguimiento de la CEDAW por sus siglas en inglés, Convención sobre la Eliminación de toda forma de Discriminación contra la Mujer (Asamblea General de las Naciones Unidas 1979) reconoce los avances obtenidos en términos de participación políticoelectoral de las mujeres en México a nivel federal, destacando el impacto positivo que ha tenido la acción afirmativa implementada bajo la figura de las cuotas de género para que las mujeres ingresaran en iguales porcentajes que los hombres a la política y se tuvieran mejores propuestas y leyes para beneficio de la población. Por primera vez en la historia de la conformación legislativa federal en México, las mujeres ocupan un porcentaje mayor a $30 \%$ en ambas Cámaras, como resultado de las reformas electorales federales, tanto administrativas como jurisdiccionales, durante el Proceso Electoral Federal 2011- 2012. Sin embargo, en el ámbito local de Nuevo León, queda camino por recorrer para alcanzar la igualdad.

La figura de lo femenino sigue expuesta a una vulnerabilidad continua, es por tanto un asunto político proyectado con diferentes discursos que enmascaran su realidad, inclusive en la esfera de personas con alguna discapacidad (Estrada y Zárate, 2016). Ante esta situación de evidente desigualdad, la reflexión que en este trabajo se construye, abona a la toma de conciencia para la no discriminación, a reflexionar en la igualdad entre mujeres y hombres para erradicar los procesos de naturalización de la violencia (Bourdieu, 1998), que existen en la sociedad y sobre todo, para mostrar con argumentos que los discursos pueden cambiar a uno de solidaridad, donde se usen los argumentos de atenuación e intensificación para mostrar diálogos de igualdad y justicia social donde no se le discrimine a la mujer por el simple hecho de serlo. Las representaciones de las mujeres impuestas por el sistema sexo-género en la sociedad 
mexicana siguen estereotipadas en la subordinación para ser contempladas como el segundo sexo (Maffia, 2007).

\section{MARCO TEÓRICO Y METODOLOGÍA}

Este trabajo plantea una aproximación al análisis pragmático de la atenuación e intensificación en la argumentación a partir de un modelo operativo (Zárate, 2012; 2015; Toulmin, Rieke y Janik, 1979; Gilbert, 1997), en el cual se identifican marcadores evidenciales y marcadores epistémicos (de Haan, 1999), presentes en el discurso político y de género. El modelo operativo de argumentación (Zárate, 2012; 2015: 175) articula las ideas propuestas en el modelo de Toulmin, Rieke y Janik (1979), reconceptualizadas a partir del modelo original planteado por Toulmin en 1958, así como también los modos de argumentación emocional, visceral y kisceral formulados por Gilbert (1997).

Figura 1. Modelo operativo de argumentación (Zárate 2015)

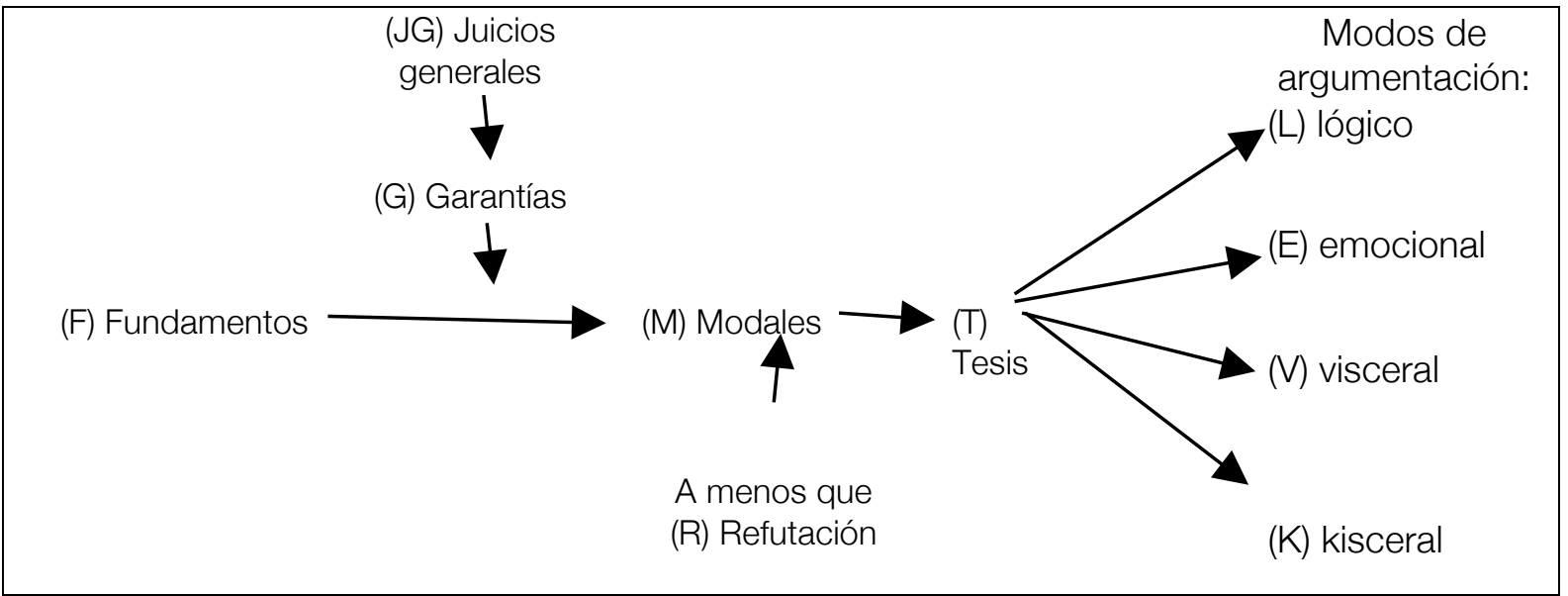

Este modelo operativo incluye los elementos de: (F) fundamentos que apoyan la tesis que se pretende defender (Toulmin, 1995/1958, p. 97); (JG) juicios generales que por lo regular están supuestos en las garantías, tales como estatutos legales vigentes, leyes científicas, etc. (Toulmin, 1995/1958: 104-106); (G) las garantías son principios, reglas, inferencias, implícitos en contraste con los fundamentos (Toulmin, 1995/1958: 98-100); (M) los modales aportan el grado de certeza de la tesis que se está defendiendo a través de ciertos adverbios como probablemente, posiblemente, seguramente o necesariamente, etc. (Toulmin, 1995/1958: 100-101); (R) la refutación indica por medio de la expresión «a menos que» alguna o algunas posibles objeciones a la tesis que se intenta defender (Toulmin, 1995/1958, p.101), (T) tesis que se pretende justificar y la cual inicia el proceso de argumentación (Toulmin, 1995/1958: 97-101, 104-106). 
Atenuación, género e intensificación en el discurso político| Olga Nelly Estrada / Griselda Zárate

La Figura 1 señala la posición de los elementos en el proceso de argumentación tradicional cuyo centro recae en el modo de argumentación lógico (L). En el discurso, sin embargo, existen otros modos de argumentación además del lógico que se acaba de explicar (Zárate, 2012; 2015: 175). En este sentido, Gilbert insiste que un modo lógico de argumentación se basa en información de fuentes racionalistas tradicionales, como garantías, respaldos, evidencias y que es explicado de manera lógica (1997:79). No obstante, al modo lógico puede añadirse el modo emocional de argumentación (E) el cual indica con una escala de grado, que pudiera ser de menor a mayor grado emotivo, el proceso de argumentación en torno a la emoción. Es prudente aclarar que este modo emocional de argumentación a veces recae en palabras o expresiones que en apariencia no evocan emotividad (1997: 83-84). El hilo de la argumentación puede adquirir el modo visceral de argumentación (V), es decir la demostración física, que puede ir desde un polo apenas evidente, por ejemplo un toque delicado de las manos, hasta el polo opuesto en la escala, un golpe o una agresión física (1997: 84).

Como se observa en el modelo operativo anterior, también la argumentación puede ser del modo kisceral (K). Gilbert acuñó este término tomando prestada la palabra japonesa ki, que denota energía o fuerza vital, como una manera de manifestar los elementos discursivos del orden de la imaginación, la intuición, la espiritualidad, la religión o mística (1997: 84-86). Este autor aclara, empero, que el modo kisceral de argumentación se mantiene dentro de una dimensión discursiva de comunicación aceptada generalmente, no presupone una dimensión del orden metafísico o religioso (1997: 87). La atenuación e intensificación en la argumentación se encuentran en los diferentes modos de argumentación, así como los otros elementos del esquema anterior, en los cuales se identifica una gradualidad en el discurso. Esto es particularmente observable en los modos emocional y visceral de argumentación, así como los (F) fundamentos, (M) modales y (R) refutación, con diferentes grados tanto de atenuación como intensificación.

Además del enfoque argumentativo teórico anterior, en el cual se muestran la atenuación e intensificación, en este trabajo se incluye también el contexto pragmático. Al respecto, puede recordarse que, la pragmática «...es una disciplina que se encarga de estudiar y plantear los principios, reglas, así como las estrategias que se siguen al usar la lengua en una situación determinada» (Briz, 2001: 67). En el discurso mediático, se observa cómo se utilizan reglas y estrategias pragmáticas dentro de un contexto determinado, que coadyuvan en el propósito de desprestigiar o enaltecer a una persona desde el instante mismo que inicia el acto de la comunicación. Cabe destacar, que de una forma u otra el/la escritor/a refleja su pensamiento y visión sobre un determinado tema y/o problema cotidiano (Briz, 2001: 365).

Aunado a los fundamentos teóricos anteriores, se realiza una aproximación a las posibles relaciones entre evidencialidad y epistemicidad (de Haan, 1999), presentes en el discurso político y de género. Se parte del concepto de evidencialidad como una manera de corroborar la información en tanto evidencia, y por otro lado, de la noción de epistemicidad como una forma de valorar el compromiso hacia la verdad (de Haan, 1999: 83). En este último caso, habría que incluir las modalidades epistémicas de probabilidad, posibilidad y certeza como grados en el continuum de verdad (de Saeger, 2007: 268), las cuales también podrían atenuar o intensificar el discurso en su dimensión pragmática. Por otra parte, en la argumentación las 
evidencias, en tanto fundamentos (F), juegan un papel determinante en la justificación de la tesis (T), especialmente en el esquema de Toulmin (1995/1958), en el cual se basa el modelo operativo de Zárate con el cual se trabaja en este análisis. En este sentido se tratan de identificar los marcadores evidenciales pragmáticos que influyen en el hilo argumentativo.

\section{DISCUSIÓN}

Participar por primera vez en las elecciones en el municipio de Apodaca, Nuevo León, México, y ganar la candidatura de su partido (PAN) fue alentador y significó estar presente en los medios masivos de comunicación y redes sociales para la diputada Marlene Benvenutti. Hubo varias variables para que ganara la elección: el PRI, el partido en el poder estaba desgastado, el género (mujer talentosa y joven), la utilización de las redes sociales para llegar a más espectadores, sobre todo, puede mencionarse el hartazgo de la gente a los mismos discursos de siempre. A un mes de haber tomado posesión como legisladora, Benvenutti realizó una protesta en contra del gasto excesivo de las cuentas públicas en el último informe del ex gobernador Medina cuyo partido es el PRI.

\subsection{Atenuación e intensificación en el discurso mediático}

En el artículo «Diputada critica al gobernador de NL y le suben fotos a las redes posando semidesnuda", escrito por Luciano Campos Garza y publicado en la revista Proceso del 28 de septiembre del 2015, se puede identificar la tesis (T): «La diputada local panista Leticia Benvenutti tomó notoriedad el pasado 24 de septiembre, durante la entrega del sexto informe de gobierno del priista Rodrigo Medina de la Cruz. Esta tesis está sustentada discursivamente por varios fundamentos $(F)$ :

1) «Al momento que el mandatario nuevoleonés daba su mensaje, la legisladora, quien es vicepresidenta de la mesa directiva del Congreso, se levantó de su asiento y mostró un cartel con la leyenda «No pasarán las cuentas mochas», en referencia a las acusaciones de desvíos que hay contra Medina».

2) «Benvenutti dijo que tras su intervención para demandar cuentas claras al mandatario, recibió una llamada telefónica intimidatoria».

3) «Y después empezaron a circular en las redes sociales imágenes que muestran a Benvenutti Villarreal en ropa íntima, en una sesión de fotografías que no tienen fecha ni procedencia».

En los fundamentos anteriores pueden identificarse el uso de estrategias pragmáticas con los marcadores evidenciales que contienen una gradualidad ascendente en la escala argumentativa. En el primero, el texto describe la acción realizada por la legisladora, además de su puesto en el congreso. Se alude a un argumento de autoridad y se intensifica el discurso al tiempo de referirse al cartel de protesta «No pasarán las cuentas mochas». En México, el término de «mochas» se usa en el lenguaje coloquial para indicar "mal hechas», "falseadas», «incorrectas», «incompletas», entre otros significados; otros, aluden a la religión como 
personas «santurronas». En el contexto de la protesta se toma la primera acepción. Al respecto, puede decirse que este fundamento cae dentro del modo visceral de argumentación, debido a la actuación física que describe el artículo, el hecho de ponerse de pie y mostrar el cartel concentrando la atención en sí misma durante la protesta, como una una estrategia pragmática de intensificación que contiene un alto grado de emotividad.

Puede decirse, en consecuencia, que la principal función de la intensificación es «hacer que algo tenga mayor intensidad para conseguir persuadir y convencer al interlocutor» (Albelda, 2005: 15). En la acción comunicativa que realizó la diputada Benvenutti al pararse atrás del gobernador y exigir cuentas claras, la persuasión estaba dirigida al auditorio como una manera de exhibir los hechos corruptos del gobierno saliente. El gobernador leyó el cartel al momento de estar dando su último mensaje al Estado, fue en ese momento cuando un reportero tomó la fotografía y circuló de inmediato en las redes sociales haciéndose viral, sobre todo por Facebook y Twitter. En el hilo argumentativo el discurso mediático captura esta intención.

En los otros dos fundamentos $(F)$, los verbos «decir», «empezar», «mostrar», fungen como marcadores evidenciales en la argumentación del texto periodístico. Ambas oraciones presentan la cadena de eventos a raíz de su protesta en el congreso, como acciones congruentes al golpeteo político, la llamada telefónica de amenaza así como las fotografías de su trabajo anterior de modelo. En ese instante, la representación socio-discursiva de Benvenutti es la de una política que critica el reporte que efectúa el mandatario. El artículo refiere estos hechos agresivos hacia la imagen social de la diputada, la publicación de fotografías -sin relación alguna con el incidente ocurrido en el Congreso-, en las cuales Benvenutti proyecta la representación social de una modelo de ropa íntima. Sin embargo, en la formación imaginaria colectiva sexista que se atribuye a las legisladoras en el noreste mexicano, tal hecho constituye una transgresión al rol asignado a la mujer. Se infiere que los contrarios de su partido llevaron a cabo este acto para intimidarla como una campaña de desprestigio, ya que ella es la presidenta del comité de vigilancia en el cual se aprobarían los presupuestos de la administración pasada.

El texto concentra la intensificación pragmática y el modo emocional de argumentación (E) en la cita de la legisladora que reproduce: «'Son fotos de las que no tengo que avergonzarme. Que se avergüencen los que roban, los que dejan un estado endeudado, los que se llevan el dinero del estado", dijo", en la cual el verbo "decir», como marcador evidencial y estrategia pragmática, manifiesta la refutación de la legisladora hacia los hechos mencionados anteriormente en el golpeteo político. Por otro lado, el modo lógico de argumentación (L) se indica en: «Explicó que las fotografías fueron tomadas hace «ocho o nueve años» y publicadas en una revista internacional de nombre no especificado. Dijo que las imágenes son de dominio público y formaron parte de una sesión que hizo, junto con otras compañeras, durante su etapa como conductora de TV». En este ejemplo, los verbos «explicar» y también, «decir» y «ser», funcionan como marcadores evidenciales. Por otro lado, implícitos en el discurso mediático, pueden mencionarse a las garantías $(G)$ como el derecho a la libertad de expresión y también, los juicios generales (JG) respaldados por la Constitución Mexicana. 
Por otro lado, el texto «Difunden fotos de Diputada en lencería», de Perla Martínez y Angel Charles, aparecido en el periódico El Norte, el 29 de septiembre de 2015, enfatiza el hecho de la publicación de las fotografías en el título. Se muestra la tesis $(T)$ «A cuatro días de que protestó contra el Gobernador Rodrigo Medina, cuando éste rindió su Sexto y último Informe, la Diputada local panista Leticia Benvenutti fue exhibida en redes sociales con fotografías en lencería», la cual está sustentada por diversos fundamentos (F) como sigue:

1) «Las imágenes forman parte de una sesión que la ahora Diputada realizó en el 2006, cuando trabajaba para el canal de videos gruperos Bandamax, y se publicaron en una revista de circulación nacional para caballeros».

2) «La legisladora albiazul es segunda secretaria en la mesa directiva y el jueves pasado sacó una pancarta de reclamo frente al Gobernador durante el Informe».

3) «Este hecho molestó a los priistas, quienes advirtieron que buscarían sacarla de la Mesa Directiva del Congreso».

En el primer fundamento el texto describe la situación de las fotografías a través de los marcadores evidenciales de las construcciones verbales «las imágenes forman parte de una sesión», "cuando trabajaba» y "se publicaron». El fundamento dos indica un marcador epistémico al decir el puesto jerárquico de la diputada «la legisladora albiazul es segunda secretaria». En el tercer fundamento se identifica un nivel de intensificación emocional en la argumentación por medio de los verbos «molestó», «advirtieron» y «buscarían sacarla».

La emotividad anterior también se hace presente en el modo emocional de argumentación en la cita «Por la noche la Diputada agradeció en su cuenta de Facebook el apoyo de la comunidad ante lo que calificó como un «ataque de personas misóginas» que buscan lastimar su dignidad e imagen», en la cual los verbos «agradeció», "calificó» y «buscan lastimar» denotan un alto grado de emoción y por ende, de intensificación argumentativa. En este tenor, el texto reproduce, además de «ataque de personas misóginas», también la siguiente cita de las palabras de la diputada Benvenutti al respecto: ««No me avergüenzo absolutamente de nada, vergüenza es robar y desfalcar al Estado», publicó». En este sentido, la estrategia pragmática de intensificación en cuanto emotividad sube en la escala argumentativa al duplicar las declaraciones de la legisladora, al defender su actividad profesional previa como modelo y contrastarla desde un punto de vista ético con el robo a la ciudadanía y al Estado.

Por otra parte, el modo lógico de argumentación (L) se describe en la cita «Ayer, los tricolores hicieron un apercibimiento por la actitud de Benvenutti» como una consecuencia esperada en la política por la acción de la diputada en el Congreso. Las palabras denotan la inconformidad de los diputados del PRI mientras que la expresión verbal «hicieron un apercibimiento» funciona como marcador evidencial pragmático. 


\subsection{Refutación de la diputada Benvenutti}

Dentro de la polémica a raíz de su protesta en el Congreso, la legisladora Benvenutti tuvo la oportunidad de defender su postura en las redes sociales por medio de su página personal de Facebook, el $1^{\circ}$ de octubre de 2015. Esta declaración fue reproducida en el medio de Quorum informativo, el cual adoptó un enfoque de género en el artículo «Campaña misógina vs Diputada por exigir cuentas al gobernador de Nuevo León». En la refutación de la diputada Benvenutti en Facebook, puede señalarse la tesis:

«Soy una mujer neolonesa, madre de familia y profesionista, que aspira a tener un mejor estado y un mejor país, y si hoy soy la portavoz del clamor ciudadano que pide justicia y sanciones para los funcionarios corruptos, lo haré con todo el honor y derecho que merece esta encomienda de Diputada local».

Como se observa en la cita anterior, la diputada Benvenutti utiliza un modo emocional de argumentación mediante marcadores pragmáticos que funcionan como intensificadores, tales como los verbos "Soy", "que aspira», «haré,, «merece», el adverbio «mejor», sustantivos "portavoz del clamor ciudadano», «justicia y sanciones», "honor y derecho», "encomienda», adjetivo «corruptos». En algunos casos, la atenuación pragmática en el discurso argumentativo funge también como intensificadora (Márquez, 2012). En el ejemplo, esta situación pudiera indicarse en «y si hoy soy la portavoz del clamor ciudadano que pide justicia y sanciones para los funcionarios corruptos,» en la cual la diputada Benvenutti atenúa el discurso como una manera de solidarizarse con el auditorio, con los ciudadanos nuevoleoneses, y sin embargo, este mismo discurso actúa como intensificador porque subraya la protesta que ella realizó en el Congreso estatal.

En este mismo sentido, puede indicarse la intensificación discursiva pragmática en: «Esta estrategia de desprestigio hacia la mujer, lejos de desanimarme, la enfrentaré sin ningún titubeo. Por ello lo digo y ahora con mayor fuerza, las cuentas públicas de los corruptos no pasaran, [sic] seguiré firme con la postura, no a la cuentas mochas de...», cuyo mensaje reitera los usos pragmáticos de intensificación en marcadores a través de marcadores como «lejos de desanimarme, la enfrentaré con absoluta transparencia», "Por ello lo digo y ahora con mayor fuerza», entre otros. Lo anterior como una manera de señalar el concepto de lucha y de posesión de la verdad, toda vez que se incluye argumentativamente mediante el marcador discursivo de «Esta estrategia de desprestigio hacia la mujer» hacia las mexicanas en general no solamente hacia la propia diputada Benvenutti.

Por otro lado, en el hilo de la argumentación a decir con Briz (2001: 110), la intensificación y la atenuación son dos estrategias discursivas derivadas de la actividad argumentativa y de la actividad conversacional de negociación del acuerdo. En tal proceso negociador, se trata de ser claro, de dar fuerza argumentativa a lo dicho o al acto de decir, de reforzar el estado de cosas que se presenta como real y verdadero y, si la argumentación lo requiere, vehemente. En este caso, la diputada Benvenutti emplea una estrategia pragmática de atenuación en el discurso, cuando menciona en el fundamento $(F)$ : 
«No me avergüenzo absolutamente de nada, vergüenza es robar y desfalcar al Estado. Esas fotos pertenecen a una etapa de mi vida en el año que fui conductora de televisión en donde recibí una invitación de la revista Maxim a salir con diferentes compañeras del medio como Daniela Cosan, Angelique Boyer entre muchas otras y fue una decisión en la que mi familia me apoyo». (Declaración de la diputada Marlene Benvenuti publicada en su página de Facebook y reproducida en: http://quoruminformativo.com.mx/index.php/2015/10/01/campana-misogina-vsDiputada-por-exigir-cuentas-al-gobernador-de-nuevo-leon/)

En este caso la estrategia pragmática de atenuación recae en el uso de argumentos de autoridad, al mencionar a la revista Maxim, así como a otras modelos y especialmente, a la familia, operan como marcadores evidenciales. Puede decirse, por tanto, que la atenuación en el discurso sirve para restarle importancia a la difusión de las fotografías; los elementos discursivos en esta frase funcionan como marcadores epistémicos al mencionar "que fui conductora», mientras que la primera oración de la cita: "No me avergüenzo absolutamente de nada, vergüenza es robar y desfalcar al Estado", actúa como una manera de reforzar e intensificar las acciones del gobierno estatal saliente, en la cual se concentra el modo emocional de argumentación mediante del adverbio "absolutamente» y los verbos «avergonzar», «robar» y «desfalcar», como se observa en el análisis.

\section{DISCUSIÓN DE LOS RESULTADOS}

En los artículos, «Diputada critica al gobernador de NL y le suben fotos a las redes posando semidesnuda", escrito por Luciano Campos Garza, publicado en la revista Proceso del 28 de septiembre del 2015, y «Difunden fotos de Diputada en lencería», de Perla Martínez y Angel Charles, aparecido en el periódico El Norte, el 29 de septiembre de 2015, se observa una incidencia de marcadores evidenciales y ningún ejemplo de epistemicidad, como se aprecia en la Figura 2. Lo anterior muestra el hecho de que en el discurso mediático se trata de enfatizar o hacer referencia a la fuente de información, lo cual se refuerza en el modelo operativo de argumentación (Zárate 2012; 2015) usado en este trabajo. Por otra parte, la ausencia de marcadores epistémicos indica, en este sentido, que en estos textos no se cuenta con la certeza o probabilidad de los hechos. 
Figura 2. Evidencialidad y epistemicidad

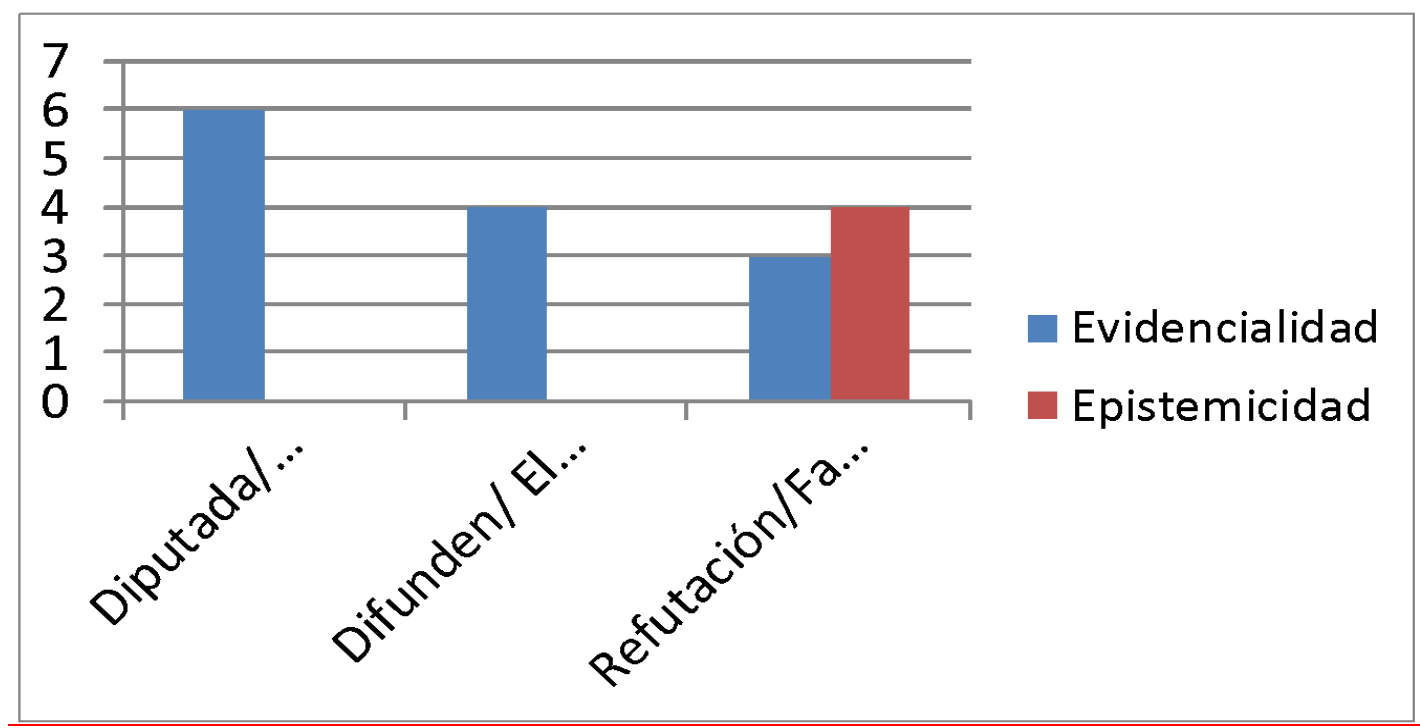

La refutación que hizo la diputada Benvenutti, en su página personal de Facebook, el $1^{\circ}$ de octubre de 2015, reproducida también por el medio Quorum informativo, contiene estrategias atenuadoras y también intensificadoras. La epistemicidad se manifiesta en cuatro casos. Esto significa el mayor grado de conocimiento del caso por parte de Benvenutti, en tanto que en los artículos periodísticos, como ya se ha mencionado, se hace un discurso referido señalando la fuente de información.

La recurrencia de marcadores discursivos de argumentación emocional, especialmente en el caso de la refutación de la diputada Benvenutti es utilizada como estrategia pragmática de intensificación, con cuatro incidencias, de acuerdo a la Figura 2. Asimismo, puede mencionarse que en los artículos de Proceso y El Norte, la intensificación en el discurso mediante marcadores de argumentación emocional está señalada mediante citas de la propia diputada Benvenutti. Por otro lado, la epistemicidad en la refutación en la página de Facebook muestra el grado de conocimiento del caso por parte de Benvenutti, en contraposición a los textos periodísticos, lo cual se manifiesta en los tres escritos.

\section{CONCLUSIONES}

A manera de conclusión, puede indicarse que el presente trabajo representa una primera aproximación al análisis del fenómeno pragmático de la atenuación e intensificación en la argumentación (Zárate, 2012; 2015; Toulmin, Rieke y Janik ,1979; Gilbert, 1997), así como a las posibles relaciones entre evidencialidad y epistemicidad (de Haan, 1999), incluidos en los discursos mediático, político y de género en el entendido que todo acto de habla implica una amenaza y por ende, un acto de poder (Briz, 2001). Lo anterior es aplicado al caso de una 
legisladora mexicana que rompe con el protocolo dentro de la Cámara de Diputados en el último informe del gobernador al mostrar una pancarta de protesta.

Se presenta el análisis de las reacciones mediáticas sobre los hechos desencadenados a raíz de la protesta en dos artículos, "Diputada critica al gobernador de NL y le suben fotos a las redes posando semidesnuda», revista Proceso, 28 de septiembre del 2015 y, «Difunden fotos de Diputada en lencería», el periódico El Norte, 29 de septiembre de 2015, así como la réplica que hizo la diputada Benvenutti en las redes sociales para defender su cargo como legisladora, reproducida en Quorum informativo. Los resultados reflejan que en el discurso mediático se privilegia la referencia a la fuente de información, con lo cual se hace hincapié en la evidencialidad, lo cual se fortalece en el modelo operativo de argumentación (Zárate 2012; 2015). La estrategia pragmática de intensificación se manifiesta mediante marcadores de argumentación emocional provenientes de citas de la legisladora Benvenutti. Por otra parte, la ausencia de marcadores epistémicos indica que en estos textos no se cuenta con la certeza o probabilidad de los hechos. La epistemicidad se encuentra en el texto de refutación que realiza la diputada Benvenutti en su página de Facebook, el cual muestra el grado de conocimiento del caso por su parte, lo cual contrasta con los otros dos textos periodísticos. Asimismo, puede señalarse el uso de la atenuación en ese texto de réplica de la legisladora como una estrategia pragmática, en apariencia para atenuar el discurso, pero cuyo objetivo es la intensificación argumentativa.

Puede subrayarse que en el texto de réplica se utilizan diversos recursos atenuadores del discurso como estrategia pragmática para proyectar y defender la imagen de mujer política de la diputada Benvenutti ante la opinión pública de Nuevo León y de México, dada la repercusión de la noticia a nivel local y nacional. Debe comentarse que desde la llegada de las mujeres a las curules del Congreso mexicano, gracias a la lucha de las mujeres de principios del siglo XX que protestaron por el sufragio, la figura de lo femenino ha seguido expuesta a una vulnerabilidad continua; es un asunto político con diferentes discursos que enmascaran realidad. Como afirma Sherry Ortner (1979), las mujeres están socialmente desvalorizadas a causa de la relación simbólica con la naturaleza debido a sus funciones reproductoras y lo masculino es más valorizado de acuerdo a la cultura, lo cual continúa siendo válido en las representaciones de las mujeres impuestas por el sistema sexo-género en la sociedad mexicana siguen siendo, sexistas, discriminatorias y excluyentes.

La situación anterior otorga un cariz de vulnerabilidad en el espacio político y de hegemonía masculina a las mujeres actuales, aún en el caso de funcionarias públicas, como el caso de la legisladora Benvenutti, a pesar de ocupar puestos de gran relevancia y tener estudios universitarios, su condición de género las vuelve vulnerables. Su protesta por la corrupción del gobierno estatal saliente desencadenó un escándalo mediático, incluyendo la publicación de fotografías de un trabajo previo suyo en lencería, como una forma de amedrentarla. Los textos periodísticos, además de la refutación, objeto del presente análisis, retoman este evento de la protesta de la diputada. La divulgación de las fotografías, sin embargo, tuvo el efecto contrario, la popularidad de la legisladora aumentó. Al respecto, puede comentarse que Marta Lamas, especialista en género, reconoció su valentía por contestar que no es vergüenza posar para una revista. De acuerdo a esta teórica, la gente está despertando porque vieron que era más 
grave el asunto de la corrupción, que el posar en lencería (Lamas, 2015). Sin embargo, si hubiera sido hombre quien hubiera trasgredido las normas del poder, la historia hubiera sido otra. La carga del género otorga significados diferentes a cada sexo dependiendo de la cultura. La problemática que se plantea en este análisis mediático y de género busca dar cuenta de cómo los medios a través de las redes sociales y la instancia política utilizan, como señala Agamben (2011) ${ }^{1}$, estos mecanismos de poder para dañar la imagen de la legisladora y silenciarla. La población nuevoleonesa reaccionó favorablemente hacia la diputada Benvenutti ante este caso «sui generis» de la política mexicana.

\section{REFERENCIAS BIBLIOGRÁFICAS}

Agamben, Giorgio (2011): «¿Qué es un dispositivo?» Sociológica, 26 (73), 249-264.

Albelda MARCo, Marta (2005): La intensificación en el español coloquial. Tesis doctoral. València, Universitat de València.

AlBALADEJO MAYORDOMO, Tomás (1989): Retórica. Madrid: Síntesis.

ARROM, Silvia (1980): La mujer mexicana ante el divorcio eclesiástico (1800-1857): Cd. de México, Secretaría de Educación Pública, México.

AsAmblea GenerAL DE LAS NACIONES UnIDAS (1979): "Convención sobre la Eliminación de Todas las Formas de Discriminación contra la Mujer». Nueva York: Asamblea General de Naciones Unidas. http://www.un.org/womenwatch/daw/cedaw/text/sconvention.htm

BENVENUTTI, Marlene (2015): Entrevista personal en el Congreso de Nuevo León, 8 de noviembre de 2015.

BOURDIEU, Pierre (1998): La dominación masculina: Barcelona, Anagrama.

BRIz GómeZ, Antonio (2001): El español coloquial en la conversación. Esbozo de Pragmagramática: Barcelona, Editorial Ariel. $2^{\mathrm{a}}$ ed.

BRIZ GómEZ, Antonio (2003): «La estrategia atenuadora en la conversación cotidiana Española», en Bravo, Diana, ed., Actas del Primer Coloquio del programa EDICE. La perspectiva no etnocentrista de la cortesía: Identidad sociocultural de las comunidades hispanohablantes. Estocolmo, Universidad de Estocolmo, 17-46

CONSEJO NACIONAL PARA PREVENIR La Discriminación (2010): Encuesta Nacional sobre Discriminación en México. ENADIS 2010. Resultados sobre Zonas Metropolitanas. Ciudad de México, Guadalajara y Monterrey. [en línea]: http://www.conapred.org.mx/index.php?contenido=noticias\&id=1000\&id_opcion=334\&op=448 [Consulta: 20/1/2016].

HAAN, Ferdinand de (1999): «Evidentiality and Epistemic Modality: Setting Boundaries», Southwest Journal of Linguistics, 18, 83-101.

SAEGER, Bram de (2007): «Evidencialidad y modalidad epistémica en los verbos de actitud preposicional en español». Interlingüística. 17. 268-277.

ESTRADA, Olga Nelly (2012): Vivencias, realidades y utopías. Mujeres, género y feminismo. Monterrey, UANL.

ESTRADA, Olga Nelly e Irma Alma OCHOA (2013): «Ficciones, realidades y utopías de la liberación sexual de las mujeres a través del feminismo en México». Estudios de Antropología Sexual, 1(4), 165-184. [en línea]: file:///C:/Users/usuario/Downloads/819-11346-1-PB\%20(2).pdf

EstRADA, Olga Nelly y Griselda ZÁRATE (2016): "Disability, Gender and Narratives of Pain: The Caregivers' Perspectives". Cultural and Religious Studies, 4, 1, 28-36, http://dx.doi.org/10.17265/23282177/2016.01.003

FLORES, María Eugenia y Olga Nelly ESTRADA (2016): El análisis del discurso político: una herramienta epistemológica para deconstruir el sexismo lingüístico. En Angélica Mendieta y David Cadevilla, coord. Educación Superior, Formación, Investigación y Evaluación, Puebla, Piso 15.

GILBERT, Michael A (1997): Coalescent Argumentation. Mahwah, Lawrence Erlbaum Associates, Publishers.

\footnotetext{
${ }^{1}$ Se entiende por dispositivo de poder «todo aquello que tiene, de una manera $u$ otra, la capacidad de capturar, orientar, determinar, interceptar, modelar, controlar y asegurar los gestos, las conductas, las opiniones y los discursos de los seres vivos" (Agamben, 2011: 257).
}

Normas (ISSN: 2174-7245)| 
INSTITUTO ELECTORAL FEDERAL, INFORME SOBRE LA EVOLUCIÓN NORMATIVA Y LAS MEDIDAS AFIRMATIVAS PARA LA APLICACIÓN efectiva de las Cuotas de Género en el Proceso Electoral Federal 2011-2012. Agosto, 2012, http://genero.ife.org.mx/docs/ife-event_InfCuotas_ago2012.pdf recuperado el 10 de noviembre del 2015.

MAFFIA, Diana (2007): «Epistemología feminista: La subversión semiótica de las mujeres en la ciencia». Revista Venezolana de Estudios de la Mujer 12, 28, 63-98.

MÁRQUeZ GUERRERO, María (2012): «La paradoja de la atenuación en el discurso político. Su funcionalidad argumentativa en las interpelaciones de parlamentarias y parlamentarios andaluces». Discurso y sociedad, 6(1), 28, 187-215.

ORTNER, Sherry (1979): «¿Es la mujer con respecto al hombre lo que la naturaleza con respecto a la cultura?», en Harris y Young, comp. Antropología y feminismo, Barcelona, Anagrama.

SERRET, Estela (2001): El género y lo simbólico. La constitución imaginaria de la identidad femenina. Ciudad de México, Universidad Autónoma Metropolitana, Azcapotzalco.

TOULMIN, Stephen, Richard RIEKE and Alan JANIK (1979): An Introduction to Reasoning. New York, Macmillan Publishing.

ZÁRATE, Griselda (2011): La identidad narrativa en la memoria revolucionaria de Andrea Villarreal. The Latin Americanist. 55, 1, 17-32.

ZÁRATE, Griselda (2012): El exilio del ningún lugar. Las voces utópicas de la familia Villarreal González. Tesis doctoral. Monterrey: ITESM (220-231).

ZÁRATE, Griselda (2015): «Argumentación en los textos de Andrea Villarreal (1907-1910)». Lenguas en contexto, 12, 173-184. 